\title{
Inclusión digital no es inclusión social: De la ilusión de libertad al hiperconsumismo tecnototalitario
}

\section{Digital inclusion is not social inclusion: From freedom illusion to totalitarian hyper-consumerism}

\section{Inclusão digital não é inclusão social: De la ilusión de liberdade ao hiperconsumismo totalitario}

\author{
Diego Levis \\ Universidad de Buenos Aires, Argentina \\ Autor referente: diegolevis@gmail.com
}

Historia Editorial

Recibido: 10/05/2017

Aceptado: 10/10/2017

"No existe, probablemente, ningún dominio del pensamiento o de la actividad material del hombre, del que se pueda decir que la cibernética no tendrá, tarde o temprano, un papel que jugar." Georges Boulanger, El dossier de la cibernética, utopía o ciencia de mañana en el mundo de hoy, 1968

\section{RESUMEN}

En 1996 J.P. Barlow, co fundador de la Electronic Frontier Foundation, presentó en el Foro Económico Mundial una declaración de Independencia del Ciberespacio. En sus conclusiones afirmaba que Internet conducirá "a una civilización más humana y hermosa". La proclama sirvió de espaldarazo para la expansión mundial de Internet, asociada a promesas de mayor libertad, democracia y prosperidad.
Desde entonces distintos sectores reclaman acciones que impulsen la inclusión digital, imponiendo la idea de que el acceso a dispositivos informáticos conectados a Internet es condición necesaria para mejorar las condiciones de vida de las capas más desfavorecidas de la sociedad. Han transcurrido dos décadas desde que estas promesas se formularon y cerca de la mitad de la población mundial 
tiene acceso a Internet. La inclusión social prometida (y deseada) está lejos de ser alcanzada. Sin embargo, la propia estructura atomizada de Internet y el uso de pantallas y de servicios telemáticos por fuera de los centros de poder ofrecen la oportunidad de explorar y desarrollar nuevos modelos sociocomunicativos que favorezcan el surgimiento de condiciones favorables para una verdadera emancipación social, económica y cultural.

Palabras clave: Pantalla; Emancipación; Control; Tecnototalitarismo

\section{ABSTRACT}

In the 1996 World Economic Forum, J.P. Barlow, co-founder of the Electronic Frontier Foundation, presented a "Declaration of the Independence of Cyberspace". In his conclusion, he claimed that that the Internet would lead to a "more humane and fair civilization". This announcement served as a boost for Internet expansion worldwide, associated with promises of greater freedom, democracy and prosperity. Since then, different social actors have been asking for digital inclusion initiatives, which hold the idea that access to internet connected devices is a necessary condition to improve life quality of disfavoured social groups. Two decades have passed since this statement was made, and almost half of the world's population has Internet access. The promised (and desired) social inclusion is far from being achieved. Nevertheless, the fragmented structure of the Internet itself and the use of screens and telematic services outside power centers, offer opportunities for exploring and developing new sociocommunicative models that foster the emergence of favourable conditions for a true social, economic and cultural emancipation.

Key words: Screen; Emancipation; Control; Techno-totalitarianism

\section{RESUMO}

J.P. Barlow apresentado em 1996 no Fórum Econômico Mundial, A Declaração de Independência do Ciberespaço que conclui que a Internet vai levar "a uma civilização mais humana e bonita." A proclamação serviu como um impulso para a expansão global da Internet, juntamente com promessas de maior liberdade, democracia e prosperidad. A partir de diferentes acções setores que promovem a inclusão digital é procurado, impondo a ideia de que o acesso a dispositivos conectados à Internet é necessário para melhorar as condições de vida das camadas mais desfavorecidas da sociedade. Depois de duas décadas desde então, e cerca de metade da população mundial tem acesso à Internet. Embora não tenha sido alcançado (e desejado) inclusão social prometida, a estrutura fragmentada da própria Internet eo uso de ècras e serviços telemáticos fora centros de poder oferecer a oportunidade de explorar e desenvolver um novo modelo sociocomunicativo com objetivo para criar condições favoráveis para uma verdadeira emancipação social, econômica e cultural.

Palavras chave: Ecrã; Emancipação; Controle; Techno-totalitarismo 


\section{1- Antecedentes: La socio-informatización, un proyecto político y empresarial}

principios de febrero de 1996, John Perry Barlow, co-fundador de la Electronic
Frontier Foundation (E.F.F.), proclamaba la independencia del Ciberespacio ante los principales dirigentes políticos y empresariales del mundo reunidos en Davos con motivo del Foro Económico Mundial.

La World Wide Web (W.W.W.) que por entonces comenzaba a popularizarse, competía en la consideración de gobiernos y empresas con la propuesta de construir con financiación de capital privado, "Autopistas de la información" (redes de banda ancha) promovida por la Comisión Europea y por el gobierno de los Estados Unidos a través de Al Gore, vicepresidente en la época.

El documento que presentó Barlow en Davos, a pesar de su carácter provocativo y aparentemente antisistema, terminó sirviendo como espaldarazo para la expansión mundial de Internet, en particular de la W.W.W., bajo el control de las grandes empresas de los sectores informático y de telecomunicaciones y el padrinazgo del gobierno de EEUU, de la Unión Europea y de organismos multilaterales (UNESCO, ITU, Banco Mundial, OCDE, CEPAL, etc).

La "Declaración de Independencia del Ciberespacio" de la E.F.F. presenta el espacio simbólico que abre Internet como un (no) lugar a-territorial en el que las reglas y leyes que regulan el funcionamiento de los estados no tienen vigencia ni los gobiernos autoridad.

Un nuevo mundo que

está a la vez en todas partes y en ninguna parte, pero no está en donde viven los cuerpos (...) en el que todos pueden entrar, sin privilegios o prejuicios debidos a la raza, el poder económico, la fuerza militar, o el lugar de nacimiento. (Barlow, 1996, p.1) 
De tinte libertario, la proclama de Barlow manifiesta la voluntad de extender el Ciberespacio a través del planeta para que nadie pueda "encerrar el pensamiento" dando lugar, concluye, "a una civilización más humana y hermosa" que las creadas anteriormente (Barlow, 1996).

El imaginario de la cibercultura que se había desarrollado en ámbitos universitarios y contraculturales de los Estados Unidos y Canadá desde inicios de la década de 1970, y a cuya tradición respondía el texto de Barlow, resultaba en gran medida coincidente con los propósitos del poder político y económico que veían en el desarrollo conjunto de la informática y de las telecomunicaciones (telemática) una posible alternativa al modelo de desarrollo industrial basado en el uso intensivo de combustibles fósiles, puesto en cuestión tras la crisis energética de 1973.

Desde entonces, y en especial a partir del final de la Guerra Fría en 1991 (disolución de la Unión Soviética), la promesa digital aparece en el centro de las propuestas de desarrollo humano. Autores y grupos provenientes de la cibercultura, como es el caso de Barlow, así como sectores cercanos o pertenecientes a los centros de poder económico y político mundial coinciden en depositar grandes expectativas en la capacidad lenitiva de las Tecnologías de la Información y la Comunicación (TIC).

Las TIC, afirmaba un documento de la Comisión Europea publicado en 1993, son el núcleo del modelo de desarrollo del siglo XXI. La evolución hacia la sociedad de la Información es un movimiento irresistible que afecta al conjunto de la organización social y a las relaciones entre los interlocutores económicos (C.C.E.1993, p.101) Pero "no se trata de un sueño tecnológico realizable sólo en el próximo siglo", por el contrario, "esta nueva sociedad ya es una realidad y son muchos los que están empezando a sacar provecho de ella (C.C.E.1993, p.24) 
La sociedad de la Información, en la cual la vida será más fácil y más justa, anunciada por diversos autores desde finales de la década de 1960, comenzaba a hacerse realidad, al menos así se proclamaba.

Durante este período, son muchos los autores que desde distintos ámbitos y posiciones ideológicas, prevén que la expansión social del acceso y uso de las TIC producirá una mejora sustancial de las condiciones de vida material y espiritual de la humanidad (Masuda, Negroponte, Castells, Toffler, Echeverría, Bell, Heim, Benedickt, Levy, entre otros). Los medios de comunicación se hacen eco de la buena nueva digital. En la presentación de un suplemento dedicado al futuro de las redes de comunicación, publicado simultáneamente en marzo de 1995 por algunos de los diarios más prestigiosos del mundo, entre ellos El País (España), La Jornada (México), Le Monde (Francia), The Independant (Gran Bretaña) y el New York Times (EEUU) se pronostica:

Si hoy cabe hablar de un solo mundo se debe, fundamentalmente, al formidable avance de las comunicaciones electrónicas (...) El siglo XXI será aquel en el que la humanidad más sepa de sí misma, más hable consigo misma, efectúe el mayor número de funciones de la sociabilidad a través del gran torrente catódico que nos inunda (World Media Network, 1995, p. 1).

Hay quienes afirman que el advenimiento de estas tecnologías representa una revolución comparable a la que significó la primera revolución industrial o la invención de la imprenta tipo móviles.

En la actualidad el mundo está asistiendo a una mutación de los sistemas de producción, la organización del trabajo y las pautas de consumo cuyos efectos son comparables a los de la primera revolución industrial. Esta mutación se debe al desarrollo de las tecnologías de la información y la comunicación (CCE, 1993, p.24). 
La hipótesis de base del razonamiento tecno-determinista consiste, señala Wolton (1992), en pensar que un instrumento, por su uso, puede tener una influencia determinante sobre los comportamientos sociales. Sin embargo, las herramientas de comunicación, por sí mismas, no son suficientes para crear transformaciones en el seno de una sociedad ni en sus prácticas comunicativas. Estas dependen del modelo de organización social.

El optimismo imperante a principios de la década de 1990 entre los responsables políticos y económicos europeos y norteamericanos acerca de las repercusiones económicas, sociales y culturales de las TIC, esconde una lucha encarnizada por el control de los dispositivos de conexión y por la hegemonía sobre las normas y los sistemas técnicos. Lo que estaba en juego, según precisa la prensa de la época, era "el negocio del siglo: las superautopistas de la información" (El País, 1994; suplem. Negocios, $9 / 10$ p.1)

No obstante, los principales beneficiarios de este enfrentamiento no fueron, en primera instancia, las grandes empresas de los sectores de la informática y las telecomunicaciones. La expansión de Internet a partir de la popularización de la W.W.W. a mediados de la década de 1990, y de las distintas aplicaciones de software y de servicios que se desarrollan alrededor de la por entonces novedosa red hipermedia (buscadores, editores de sitios web, webmail, etc.) surgen en ámbitos cercanos a la universidad y a la contracultura, de mano de iniciativas de jóvenes informáticos influidos por la cibercultura, un proyecto social y técnico que fomentaba la creación de herramientas telemáticas de cooperación e intercambio. "Al encontrarse ellos mismos en una situación de innovación social, concibieron dispositivos de comunicación adaptados a nuevas prácticas sociales, a nuevas representaciones de la sociedad" (Flichy, 2006). 
Las grandes empresas del sector y el sistema financiero internacional no confiaron inicialmente en la viabilidad económica del modelo de acceso abierto con el que funcionaba Internet. Prefirieron aposta por la creación de una nueva red de banda ancha de alta velocidad, una superautopista de la información como la propuesta por el gobierno estadounidense y por la Unión Europea, enfocada principalmente a la oferta de servicios arancelados. Internet, en cambio, no tenía un funcionamiento comercial ni estaba controlada por grandes empresas ni gobiernos y, sobre todo, existía y tenía millones de usuarios (alrededor de 15 millones en 1994). Esto último sería un factor determinante para su popularización, en especial a partir del lanzamiento en diciembre de 1994 de Netscape, el primer navegador web comercial (aunque de uso gratuito). Poco tiempo más tarde el concepto de superautopistas de la información desaparecería de los discursos públicos, lo cual no implica que el modelo comercial y de control en que se basaba haya sido abandonado.

Han transcurrido dos décadas desde la proclama independentista de Barlow e Internet es hoy fundamentalmente una gran red comercial y de control y, a pesar de su estructura capilar, de tráfico altamente concentrado. ¿En dónde ha ido quedando el espíritu libertario y contracultural del ciberespacio inicial? ¿Qué ha sucedido durante este tiempo?

\section{2- La inclusión digital como objetivo: De la cibercultura al infocapitalismo} avanzado.

La popularización de la Web hizo que Internet comience a ser asociada en la prensa y en otros discursos públicos a las promocionadas superautopistas de la información, cubierta por una pátina de progresismo e innovación social, cultural, educativa, política y económica deudora de las premisas de la cibercultura. Al poco tiempo esta red telemática empezó a ser vinculada con el crecimiento y consolidación de la Sociedad 
de la información y esta a promesas de mayor libertad, democracia y prosperidad para todos los habitantes del planeta. La expansión de Internet era vista como una oportunidad de desarrollo económico y humano que el mundo, y en especial los países más pobres, debían aprovechar, se afirmaba en distintos foros internacionales. Esta tecnoutopía, de acuerdo a Petrella, respondía al objetivo principal del capitalismo contemporáneo: la creación de un espacio mundial de libre comercio sin regulaciones estatales.

Los diarios y otros medios de prensa no tardaron en comenzar a publicar ediciones en línea (entre 1995 y 1996 la mayoría de los principales diarios del mundo empezaron a estar presentes en la Web), se hablaba con insistencia de comunidades virtuales formadas por usuarios de la red que comparten intereses pero viven en lugares distantes y aparecen las primeros sitios web dedicados al comercio electrónico, lo que da lugar a que en distintos ámbitos se hable del nacimiento de una "nueva economía" basada en transacciones de bienes y servicios "inmateriales". La Web comenzó a "poblarse" de nuevos "colonos", adquiriendo rasgos que la fueron alejando del ciberespacio idealizado que describe la proclama de Barlow en Davos.

No tardaron en surgir voces disonantes advirtiendo que el rumbo que comenzaba a tomar la Red se alejaba de los propósitos iniciales de libertad,

1. (...) lo que amenaza a Internet es la tentación cada vez más manifiesta, de los grandes mastodontes de la comunicación de apoderarse comercialmente de la 'red de redes'. Los mercaderes se están lanzando al asalto de Internet porque ven en el nuevo medio de comunicación una fuente inagotable de provecho (Ramonet, 1996).

Las voces críticas no fueron atendidas. La conquista mercantil del ciberespacio estaba en marcha y nada la detendría. 
La oposición entre propósitos humanistas y fines económicos expresados en informes de gobiernos y de organismos multilaterales y en la obra de diversos autores se puede rastrear en las ideas de Norbert Wiener, fundador de la cibernética (ciencia de raíz matemática que refiere al estudio del control y la comunicación en máquinas y seres vivos), quien en 1950 advertía que:

La obligación social de los dirigentes es utilizar los métodos cibernéticos para beneficio del hombre, para aumentar su tiempo libre y enriquecer su vida espiritual, en vez de emplearlos sólo con vistas a la ganancia y de adorar a la máquina como el nuevo becerro de oro (Wiener, 1969, p. 51).

Mandato que a pesar de los años transcurridos y sobretodo de la experiencia acumulada, en gran medida, mantiene aún su vigencia.

Hacia finales de siglo, en distintos ámbitos institucionales públicos y privados prevalece la idea de que el acceso a dispositivos informáticos conectados a Internet es una condición necesaria para mejorar las condiciones de vida de los sectores más pobres de la población mundial. Un nuevo mito comienza por entonces a despuntar con fuerza recuperando algunos los postulados de la ciberutopía propuesta por Masuda en la década de 1960 y otras posteriores de similar corte que consideraba que la emergente sociedad de la Información ofrecería una nueva oportunidad para la libertad y la igualdad. "Englobando la libertad de decisión y la igualdad de oportunidades. (...) la futura sociedad de la información, será una sociedad sin clases, libre de un poder dominante y cuyo núcleo social serán las comunidades voluntarias" (Masuda 1988, p.115)

Los medios de comunicación se encargan de difundir la buena nueva digital. Sin asideros factuales que revelen beneficios concretos en cuestiones sensibles como la lucha contra la pobreza y la desigualdad o mejoras en sanidad o educación (ni datos empíricos que lo justifiquen) se proclama que el acceso a computadoras y a Internet 
es un derecho social que los estados deben asegurar, dejando en un plano secundario el formidable negocio que la expansión tecnodigital representa para las empresas del sector informático y de telecomunicaciones. No es accidental que gobiernos y empresas se muestren tan activos en atribuir capacidades lenitivas a las TIC. Tengamos presente que la informática y las redes de telecomunicaciones, además de representar una gran oportunidad de crecimiento económico, son poderosas herramientas para controlar y supervisar las actividades de las personas (Levis, 1999). La cumbre del G8 (los 8 países más poderosos del mundo) celebrada en Okinawa, Japón en 2000 y la Cumbre Mundial de la Sociedad de la Información (CMSI) realizada en Ginebra 2003 y Túnez 2005 ("Plan de Acción de la CMSI”) confirman la importancia estratégica que el poder político y empresarial del mundo le otorgan a las TIC como factor universal de desarrollo social y económico.

El desafío es encauzar el potencial de la tecnología de la información y la comunicación para (...), erradicar la extrema pobreza y el hambre, lograr una educación primaria universal, promover la igualdad de género y la habilitación de las mujeres, reducir la mortalidad infantil, mejorar la salud materna, combatir el VIH/SIDA, el paludismo y otras enfermedades, garantizar la sustentabilidad ambiental y forjar alianzas mundiales en favor del desarrollo para lograr un mundo más pacífico justo y próspero (Unión Internacional de Telecomunicaciones, 2005).

Se afirma en la Declaración de principios firmada en Ginebra al termino de $1^{\underline{a}}$ Fase de la Cumbre Mundial de la Sociedad de la Información a finales de 2003. Los firmantes expresan su convicción de que las TIC brindan "oportunidades sin precedentes para alcanzar los niveles más elevados de desarrollo" (ITU, 2005), reiterando predicciones de documentos e informes de décadas anteriores. 
El objetivo, se repite, es superar la llamada "brecha digital", concepto que describe las desigualdades de acceso a redes y computadoras, tanto entre países como entre personas (conectados o no conectados) a cuya divulgación contribuyen activamente varias empresas de los sectores informáticos y de telecomunicaciones. Estas propuestas, de carácter más propagandístico que científico, insisten en atribuir a las TIC poderes lenitivos que supuestamente permitirán superar carencias y "brechas" de orden primario, en tanto hacen a la supervivencia de las personas, derivadas de la miseria (falta de agua potable, sanidad, vivienda, alimentación, etc.), evitando indagar en las causas de la desigualdad, la marginalización y de la pobreza extrema. Asimismo, se olvida u omite que las dinámicas de apropiación social de las tecnologías rara vez son lineales y que la existencia de anclajes culturales con el pasado (prácticas cotidianas, creencias, tradiciones, etc) hace necesario establecer articulaciones entre lo nuevo y lo viejo (Levis, 1999).

Han pasado más de 20 años desde la proclamación de la "Independencia del Ciberespacio" en Davos y más de una década desde la CMSI. EI número de usuarios de la Internet a inicios de 1996 apenas superaba los 20 millones de usuarios en todo el mundo mientras que a principios de 2017 se calculaba que más de 3.700 millones de personas tenían algún tipo de acceso a la Internet, prácticamente la mitad de los habitantes de la Tierra (Fte. Internet World Stats, 5/2017).

La Red actualmente, de algún modo, se superpone y ocupa una porción significativa del mundo. La vida de más de dos mil personas transcurre en un tiempo-espacio regulado por la presencia y el uso de pantallas electrónicas conectadas a una red telemática. En algunas regiones del planeta como Norteamérica y gran parte de Europa el número de usuarios supera al $75 \%$ de la población mientras que en Sudamérica alcanza más del $60 \%$ de los habitantes $(69 \%$ en la Argentina y Chile, $71 \%$ en Uruguay $71 \%$ y $67 \%$ en Brasil). En gran medida, estas cifras unidas al rápido 
desarrollo de la telefonía celular (o móvil) confirman una de las principales metas que se había marcado la CMSI para 2015: "asegurar que el acceso a las TIC esté al alcance de más de la mitad de los habitantes del planeta" (ITU, 2005).

Sin embargo, ¿Acaso por tener acceso a Internet han mejorado las condiciones de vida materiales de las personas? ¿Tenemos más y mejor democracia, menos desigualdad, mejor educación, menos pobreza y demás mejoras en nuestras vidas por el hecho de disponer de computadoras (y otros dispositivos digitales de uso personal) y de acceso a Internet y otras redes telemáticas tal como aseguran (quizás cabría decir profetizan) desde hace más de cuatro décadas los divulgadores del mito tecnodigital? ¿Quiénes han sido los principales beneficiarios del proceso de informatización de la sociedad?

\section{3- De las promesas de emancipación a la exasperación del control social y el} hiperconsumismo

La Cumbre Mundial de la Sociedad de la Información fue un gran espaldarazo para la asociación discursiva (y pragmática) entre acceso a las TIC, progreso económico e inserción social iniciada en la década de 1970. De tal modo, a partir de la celebración de la Cumbre, en distintos países del Tercer Mundo se profundiza la implementación de políticas activas destinadas a la acelerar el proceso de informatización en distintos ámbitos de la actividad pública y privadas.

Entre otras acciones, se firman acuerdos entre gobiernos y empresas de los sectores de informática y telecomunicaciones destinados a acelerar el proceso de incorporación de computadoras y redes en la administración pública y en la educación, se fomenta el uso de distintas aplicaciones y servicios de Internet en el ámbito privado y se lanzan distintos planes destinados a superar la llamada brecha digital y a facilitar la inclusión social brindando acceso a recursos tecnológicos. A las políticas públicas destinadas a 
favorecer la inclusión digital se añade la rápida expansión social de la telefonía móvil, y en particular de los llamados smartphones, que permite que personas de las capas más desfavorecidas de la población accedan a servicios avanzados de información y de comunicación a través de redes telemáticas inalámbricas. En este contexto, con un altísimo porcentaje de conectividad el proceso de inclusión digital parece estar muy bien encaminado, incluso en regiones como Norteamérica y Europa Occidental lo podríamos considerar concluido.

Sin embargo, la realidad política, cultural y económica en ningún caso parece aproximarse al mundo más humano anunciado por los ciberutopistas, como tampoco se observan logros remarcables en la construcción de la sociedad más equitativa, solidaria y libre que prometían y siguen prometiendo documentos e informes de organismos multilaterales y expertos del ámbito empresarial y/o académico. Por el contrario, en las últimas décadas los índices de concentración de riqueza y de desigualdad no han dejado de aumentar, mientras que se produce el desmantelamiento del estado del bienestar. La miseria, la violencia, la insolidaridad, la explotación laboral, la discriminación, la desesperanza, la intolerancia y la exclusión social, cultural y económica son flagelos que, en lugar de disminuir, avanzan. E mundo sigue siendo inhóspito para la gran mayoría de los seres humanos, en especial para aquellos que viven en países del Tercer Mundo. Según un informe de OXFAM, el $1 \%$ más rico de la población mundial posee más riqueza que el 99\% restante de las personas que habitan el planeta y siete cada diez personas vive en un país en el que la desigualdad ha aumentado en los últimos 30 años. "Desde el inicio del presente siglo, la mitad más pobre de la población mundial sólo ha recibido el $1 \%$ del incremento total de la riqueza mundial, mientras que el $50 \%$ de esa "nueva riqueza" ha ido a parar a los bolsillos del 1\% más rico" (OXFAM, 2016) 
En definitiva, el acceso masivo al ciberespacio y su consecuente expansión no produjo las transformaciones estructurales anunciadas, ni mucho menos un cambio civilizatorio que conduzca a la desaparición de la pobreza y de las guerras (en 2014, según el informe anual del PNUD una quinta parte de la población mundial vivía en zonas afectadas por conflictos armados)

A pesar de estos datos, desde distintos ámbitos políticos económicos y académicos se siguen renovando las promesas de mayor bienestar material y emocional, de justicia social y de libertades civiles derivadas del uso de dispositivos digitales conectados a redes telemáticas, de la innovación tecnológica y de la globalización (económica y cultural) menospreciando que "las cuestiones sociales son sobre todo cuestiones humanas de relaciones entre seres humanos integrados cada uno de ellos en su ambiente" (Ippolita, 2012, p.19)

Más allá de anuncios, de promesas y de acciones concretas impulsando la expansión social del uso de TIC, es tiempo de dejar atrás la fascinación iniciática por las utopías cibernéticas y ser conscientes que ninguna tecnología por si misma tiene (ni nunca tuvo en el pasado) la capacidad de solucionar los problemas sociales, culturales, económicos y éticos que tiene planteados la humanidad

El crecimiento exponencial de las redes telemáticas inalámbricas de alto rendimiento, la generalización del acceso a aparatos computacionales con prestaciones en continuo aumento (en especial a teléfonos celulares y otros dispositivos portátiles), de la conectividad y de las aplicaciones y servicios en red, impulsaron, en cambio, un crecimiento meteórico de las cifras de negocios de las compañías de telecomunicaciones y de dispositivos y servicios informáticos.

\section{1 - Los usos de las pantallas}

Aunque lejos de la inclusión social prometida (y deseada), el uso de pantallas y de servicios telemáticos permite realizar múltiples actividades de distinta índole, 
inimaginables hasta hace pocas décadas, modificando de forma significativa la vida cotidiana de gran parte de la humanidad. Los dispositivos portátiles como celulares "inteligentes", tabletas y netbooks brindan a cada usuario, entre muchas otras opciones, la posibilidad de conectarse (y de exhibirse) en todo momento y lugar con multitud de personas (amigos, conocidos y desconocidos) en un continuo fluir de mensajes fútiles o no, y de recibir a través de la pantalla un aluvión de contenidos y servicios de todo tipo y origen (juegos, fotografías, videos, música, turismo, etc) que, a modo de enorme vidriera de doble faz, por un lado estimulan el consumismo (de objetos, de servicios, de información, de productos culturales, etc) y por otro lado expone a cada usuario a la mirada escrutadora de empresas (y gobiernos) que con fines comerciales, propaganda política y/o control social hacen un permanente seguimiento de las acciones y el comportamiento de cada persona en la red. En tal sentido el colectivo Ippolita advierte que "las tecnologías de perfilación de Facebook, Google \& C., pueden ser usadas indistintamente para mejorar la publicidad y el consumismo personalizados, o bien para reforzar la censura y la represión personalizadas" (Ippolita, 2012, p.156) En este contexto de control y vigilancia digital los perfiles y los comportamientos personales de los usuarios en las redes adquieren un valor comercial transable (y políticamente controlable) que es una importante fuente de beneficios económicos para las principales empresas de servicios de la red. "En la sociedad expuesta cada sujeto es su propio objeto de publicidad. Todo se mide en valor de exposición" (Han, 2015, p. 29)

Los esperanzadores espacios de libertad que abrió la primigenia Internet han sido ocupados mayormente por intereses mercantiles y políticos, lo hemos remarcado antes. Pero debemos ser conscientes que no vivimos ni viviremos mejor por el sólo hecho de disponer de más (y mejores) pantallas, más imágenes, más información, más juegos y espectáculos, más canales de comunicación, "si estos están concebidos 
con el sólo objeto de mediatizar mercantilmente el conjunto de nuestras vidas" (Levis, 1999, p. 307).Tal como afirma el filósofo coreano-alemán Byung-Chul Han, retomando una idea ya expresada por Debord en La Sociedad del Espectáculo (1967), "el exceso de exposición hace de todo una mercancía" precisando más adelante que "la economía capitalista lo somete todo a la coacción de la exposición" (Han, 2015, p. 29) Afortunadamente aún perviven rescoldos de usos alternativos de la pantalla que permiten imaginar que aún cabe la posibilidad de que las redes telemáticas puedan ser efectivamente la herramienta útil para la emancipación e inclusión social que imaginaron algunos de sus pioneros. Pensamos que la propia estructura atomizada de Internet, en particular la estructura abierta de vocación universal de la Web, y su capacidad de generar (y permitir) modalidades reticulares de comunicación (de muchos a muchos) por fuera de los centros de poder, ofrece todavía la oportunidad de explorar y desarrollar un nuevo modelo sociocomunicativo en el que prime lo colaborativo sobre lo individual, que contribuya a generar condiciones favorables para una verdadera transformación social, económica y cultural. Un modelo alternativo que trascienda el determinismo crítico que desde hace décadas acompaña y válida al proceso de digitalización de la sociedad. Algunos antecedentes, largamente citados, como el uso temprano de herramientas de la la red como medio de difusión internacional, sobre el levantamiento zapatista en México a finales de 1994, hasta el nacimiento a partir convocatorias a través de la red de diversos movimientos antisistema en todo el mundo(por ejemplo los "Indignados" en España en 2011), permiten imaginar usos de los nuevos medios digitales distintos a los que priman hoy, centrados fundamentalmente en el entretenimiento y el consumo. Asimismo, la evolución posterior de dichos movimientos pone de relieve que, aunque útiles como herramienta catalizadora de las convocatorias iniciales, el uso de TIC no es condición 
suficiente para dar continuidad a (o desencadenar) procesos de verdadera emancipación social.

\section{4- De la pantalla controlada a la pantalla emancipada. Caminos digitales hacia la inclusión social}

Es difícil discutir que, tal como sostenía Ramonet (1996, p. 13), "indiscutiblemente con Internet entramos en una nueva era de la comunicación". El mismo autor sostenía entonces que "de nuevo, hay muchos que piensan, no sin ingenuidad, que cuanto más comunicación haya, más armonía social habrá. Se equivocan. La comunicación, en sí, no es progreso social."

Sin duda, nunca antes en la historia los seres humanos hemos tenido tantas posibilidades para comunicarnos y colaborar con nuestros semejantes, para expresar nuestras ideas y creencias, para difundir nuestras creaciones literarias, visuales y/o musicales, ni tampoco para conocer las ideas, opiniones y creaciones culturales, artísticas y/o científicas de personas y grupos de personas próximas o lejanas. El mundo, aparentemente, se nos abre en toda su esplendor y sin embargo, el uso intensivo de la pantalla está resultando un fiasco para quienes aún confían/confiamos (cautamente, es cierto) en el potencial emancipador de los nuevos medios digitales. Tal como afirma la investigadora mexicana Sagastegui (2005, p. 2) "no es sorprendente que presenciemos una aparente paradoja entre expectativas optimistas y pesimistas (la tecnofilia y la tecnofobia)". Esta autora señala "que repetidamente se han reportado malos resultados de la informatización de las escuelas, por ejemplo. No por ello la demanda de computadoras ha decrecido, sino al contrario" (Sagastegui 2005 , p. 2). No se trata de un caso aislado. La invocación a un futuro mejor de la mano de la revolución tecnológica se renueva permanentemente, adquiriendo los rasgos de una meta volante, a la cual, al modo del tesoro al final del arco iris, siempre 
nos mantenemos a la misma distancia, a pesar de que no dejemos de avanzar en su búsqueda.

Durante el último medio siglo el avance del individualismo y del éxito personal medido en dinero y capacidad de consumo fue disolviendo en gran medida las redes de pertenencia comunitaria y los proyectos colectivos de transformación política, social y cultural que precedieron y acompañaron el conflictivo desarrollo de la sociedad industrial. En la actual sociedad de la Pantalla, "el individuo debe asumirse de forma completamente autónoma y al mismo tiempo en interrelación permanente con los otros, éste es el modelo del individualismo en red." (Flichy, 2006).

Temerosos de la masa - en la naturaleza de la masa se observa una doble faz de sumisión y rebelión, lo que la hace en gran medida impredecible - el poder económico y político promueve con éxito la idea de que cada individuo es en sí mismo un agente autónomo de cambio y mejora de su propia vida. Este presupuesto actúa como factor de naturalización de las condiciones sociales y los valores consumistas propuestos.

El auge en los en los países occidentales de los libros de autoayuda y de las técnicas orientales de meditación, así como la popularidad creciente de los superhéroes de ficción y del deporte y la promoción del emprendurismo empresarial como modelo de superación personal (y social) ilustra perfectamente la tendencia indicada.

Impulsados por la esperanza de lograr la felicidad y el éxito, millones de jóvenes trabajadores altamente formados han aceptado trabajar en condiciones de un espantoso estrés, de sobre-explotación, incluso con salarios muy bajos, fascinados por una representación ambigua en la que el trabajador es descrito como un empresario de sí mismo y la competición es elevada a regla universal de la existencia humana (Berardi, 2003, p.10).

Este ideal conduce a lo que Han (2015b, p. 19) denomina autoexplotación, "Ya no trabajamos para nuestras necesidades, sino para el capital. El capital genera sus 
propias necesidades que nosotros, de forma errónea, percibimos como propias". El objetivo es conseguir que cada sujeto sienta que su destino personal y su bienestar se desarrollan al margen del devenir de los Otros. Lo individual se impone a lo comunitario. Los gobiernos recortan la inversión en salud, educación y previsión social que son presentadas como un gasto prescindible. En cuanto al consumo de bienes y servicios, es hora de los productos personalizados, de distinción a través de objetos y marcas de prestigio. Curioso e inédito elitismo de masa que al mismo tiempo nos separa de la masa, conjunto amorfo al cual nadie desea ni reconoce pertenecer (Levis, 1999).

Coincidiendo con esto, se pasa de la pantalla familiar del televisor a la pantalla de uso individual y portátil de netbooks, tabletas y celulares "inteligentes" que permite la recepción personalizada de contenidos producidos (o no) por las industrias culturales - Ilusión vana en un mundo crecientemente homogeneizado. "El individuo, profundamente narcisista, se centra en la exclusiva satisfacción de sus deseos y se limita a medir su vida por el rasero de sus propios derechos e interés" (Frommer, en Serrano, 2015, p. 178)

A medida que la vivencia de igualdad que proporcionaba la masa se diluye, las exigencias de justicia e igualdad van perdiendo su energía.

Cada individuo, ocupado en la búsqueda de su individualidad, abandona su identidad social, adentrándose en los vericuetos de su progresiva transformación en pura variable económica: el Homo-consumens, último eslabón de la evolución. Simultáneamente máquina de consumir y objeto de intercambio para los mercaderes de los comportamientos sociales (Levis, 1999, p. 166).

En un contexto caracterizado por la presencia ubicua de la Pantalla, el tipo de mediación que se establece entre las personas y los nuevos medios digitales adquiere 
un creciente carácter simbiótico. La Pantalla aparece integrada a la persona, cuan prótesis senso-cognitiva, trastocando nuestra percepción espacio-temporal y transformando nuestro modo de pensar el mundo y muchas veces de pensarnos a nosotros mismos. Lo social se diluye en una progresiva y definitiva disolución de todo vestigio de comunidad, en el sentido convencional del concepto, dando lugar a un nuevo tipo de relaciones sociales, caracterizadas por la fragmentación, el ocultamiento del cuerpo, la deslocalización y la intemporalidad, cuyas formas definitivas no terminan de definirse.

Con la Pantalla nadie está solo, al menos no del modo en que se solía estar solo hace apenas unos años. La Pantalla ofrece la gratificación de cierto tipo de compañía y complicidades sin las exigencias de la intimidad ni del compromiso que la presencia física imponía a las antiguas relaciones personales. Aunque la conexiones se multiplican gracias al uso de nuevos medios, las personas se relacionan menos. Las relaciones entre las personas se producen como consecuencia de un acto de voluntad consciente y este tipo de relaciones son menos espontáneas que las nacidas casualmente. Como consecuencia de esto los vínculos personales, a falta de la presencia física del otro, se vuelven más frágiles, etéreas y efímeras.

Alimentadas por un imaginario propio, en la red las vivencias personales que hasta no hace mucho quedaban en el ámbito de la vida privada se integran en un espectáculo ininterrumpido de contenidos diversos en el que es difícil distinguir la verdad de la mentira, la ficción de lo real y del que a muchas personas les resulta casi imposible desvincularse. Habituados a percibir el mundo, a realizar distintas tareas y a comunicarnos utilizando medios digitales cada vez nos cuesta más ver lo que nos rodea, reconocer nuestro entorno, mirar a nuestros semejantes. El cuerpo deja de ser el límite de nuestra experiencia. Todo parece posible en la Pantalla; imágenes y sonidos, para un espectáculo que se imbrica en el tejido de lo real. 
Sin embargo, aún cuando no siempre tenemos plena conciencia de ello, la Pantalla forma parte de la realidad y aquello que hacemos utilizando un dispositivo de comunicación en red, tiene (o puede tener) múltiples consecuencias sobre distintos aspectos de nuestra vida cotidiana $y / 0$ en la de otras personas, cercanas o no a nosotros.

La Pantalla genera una situación de tensión entre la promesa que ofrece de pluralidad, diversidad cultural, libertad de expresión y de creación y la expansión efectiva de la concentración empresarial, la homogeneización cultural y los mecanismos de control social y de vigilancia inherentes a los nuevos medios. "Los aparatos digitales traen una nueva coacción, una nueva esclavitud. (...) transforman todo lugar en un puesto de trabajo y todo tiempo en un tiempo de trabajo" (Han, 2015b, p. 59)

En este contexto, la lógica técnica impone sus reglas. Reglas que en el caso de los dispositivos informáticos, condicionan lo que está permitido hacer y el modo de hacerlo. "Un mundo ganado por la técnica es un mundo perdido para la libertad" señalan Forget y Pollycarpe (1990, p. 14) quienes advierten que "la visión técnica del mundo posee todos los rasgos del totalitarismo" (Forget y Pollycarpe, 1990, p. 145). ¿Es así?

Uno de los ingredientes fundantes de la libertad es la privacidad de los actos, ideas y emociones de cada persona. El control electrónico de nuestras vidas al que nos somete el uso de distintas aplicaciones teleinformáticas va minando poco a poco los espacios de libertad. Nosotros, voluntariamente, contribuimos a esto sin percibir el alcance simbólico y material (político, cultural y económico) de nuestras acciones en la Red. "Hasta tal punto deseamos disfrutar de experiencias online gratuitas que aceptamos gustosamente no recibir ninguna compensación económica, ni ahora ni nunca por la información que generamos" (Lanier, 2015, p. 47) Informaciones que son fuente de ganancias de las empresas que nos brindan dichos momentos de disfrute y 
simultáneamente son utilizadas por distintos centros de poder para condicionar nuestras formas de pensar, nuestros valores y hábitos de consumo e incluso nuestras decisiones políticas mediante el cruce masivo de datos (Big Data) combinados con sistemas de inteligencia artificial. Los usos que realizamos de las redes sociales, las consultas que hacemos en buscadores web, las operaciones de compra y venta en línea que realizamos y muchas otras actividades que efectuamos utilizando los nuevos medios permiten conocer de forma instantánea nuestros intereses y los de otros millones de personas, los estímulos a los que respondemos, cuándo y porque nos conectamos y con quiénes interactuamos, y mucho más (Magnani, 2017).

Al cruzar esa enorme cantidad de datos con los que tienen, por ejemplo, los bancos o las agencias estatales, según los expertos, se puede medir (y predecir) casi todo e influir en las decisiones y comportamientos de las personas. Estas técnicas de control matemático de los mensajes renuevan uno de los aspectos más inquietantes de la cibernética, cuyo propósito, expresado por Wiener en 1950, era desarrollar técnicas que "permitan no sólo encarar los problemas generales de comunicación y regulación, sino además establecer un repertorio adecuado de ideas y métodos para clasificar sus manifestaciones particulares por conceptos" (Wiener, 1969, p. 17). Propósito que expresa el ideal cibernético de una sociedad estable, regulada por medio de mecanismos sociales objetivamente controlables.

Cuanto más datos de nosotros posea el sistema más conoce sobre nuestras vidas y gracias a esto, además de controlarnos e influir en nuestras decisiones y deseos, las distintas aplicaciones en red nos pueden ofrecer un mejor servicio, facilitando muchas de las tareas que hacemos cotidianamente, desde brindarnos información y publicidad personalizada a automatizar distintas operaciones bancarias, entre multitud de otras opciones. Mediante estas y otras técnicas de condicionamiento "se conforma un nuevo 
poder disciplinario que en lugar de prohibir, seduce y es complaciente; que "en lugar de hacer hombres sumisos, intenta hacerlos dependientes" (Han, 2015b, p. 29)

La privacidad es asunto del pasado, todo queda al alcance de unos y otros, amigos, compañeros de trabajo y de estudio y también de empresas, de instituciones privadas y públicas y de gobiernos. Las personas se vigilan ahora rutinariamente las unas a las otras. Indiferentes al control y la vigilancia a la que nos entregamos, la escena se repite; una, dos, infinitas veces en cualquier momento y lugar, en ámbitos públicos y privados, registramos imágenes fijas o en movimiento de lo que estamos viviendo. "En la sociedad expuesta cada sujeto es su propio objeto de publicidad. Todo se mide por su valor de exposición" (Han, 2015, p.29). Fotos y videos a los que sumamos comentarios en los que damos a conocer nuestras opiniones sobre los más diversos temas que casi inmediatamente difundimos a través de las redes sociales exponiéndonos a la mirada de los otros. Es decir, al juicio y al control social (y gubernamental) permanente. "La potente exigencia de transparencia indica (...) que el fundamento moral de la sociedad se ha hecho frágil, que los valores morales (...) pierden cada vez más su significación" (Han, 2015, p. 92). La era digital, subraya el filósofo alemán Boris Groys (2016), es antes que nada una época de vigilancia en tiempo real.

La sociedad está hecha de cuerpos, de personas que actúan, comunican, sufren y se rebelan. Pero la red de vínculos, restricciones y automatismos producidos por el desarrollo del capital hace que esos cuerpos sean cada vez más dependientes -lo sepan o no- del funcionamiento de la red global. (Berardi, 2003, p.178).

El control y la vigilancia no sólo invaden el espacio público y el privado sino también las ideas, emociones y deseos de las personas; ante nuestra indiferencia y, en muchos casos, incluso con nuestra anuencia. "La vigilancia externa ya no es tan necesaria. En 
gran medida la sustituye a vigilancia interna. El Control, sólo funciona si uno es cómplice de él", nos recuerda Fischer (2016, p.51).

En muchos casos las prácticas sociales en la red están condicionadas de acuerdo a un "deber ser" que impele hacia el exhibicionismo y el espectáculo, convirtiendo a las personas y al mundo en mercancías. Así, la Pantalla, a modo de flautista de Hamelín, parece conducirnos hacia un hiperconsumismo tecnototalitario y discriminatorio, administrado a través de sofisticados sistemas de control cibernético del comportamiento humano. "La transparencia, en el orden cibernético, implica quedar reducidos a "perfiles". Convierte la experiencia en estadística. Pero no somos perfiles, sino singularidades con tonos, vibraciones y acentos propios" (Fernández-Savater, 2015). Los repetidos errores de encuestas y estudios similares en la predicción de resultados electores parecen confirmar uno de los límites de la exploración matemática del comportamiento humano.

Precisamente, dado que los seres humanos no somos "perfiles", nos permitimos pensar, retomando el lema de los movimientos antiglobalización de principio de siglo, que "otro mundo es posible". Debemos imaginar y construir un mundo alternativo al que se va conformando en la sociedad de la Pantalla al amparo del mito tecnodigital. Una vida en la que la libertad deje ser la libertad de las grandes corporaciones empresariales y la de buscar el interés propio a costa de los otros. Un mundo en que el interés común prime sobre los intereses individuales. Es primordial recuperar el verdadero sentido y el valor de la libertad dentro de su marco natural, la comunidad. Los nuevos medios, paradójicamente, pueden cumplir un rol importante en el logro de los propósitos enunciados, pero no será de la mano de las empresas de informática y de telecomunicaciones ni de los gobiernos que ofrecen amparo normativo a la mundialización del hiperconsumismo y al avance tecnototalitario. 
Si bien la incorporación acelerada al universo simbólico que se construye en la Pantalla tiende a generalizar prácticas de vigilancia y control social y en muchos casos incrementa las consecuencias de la exclusión, también brinda herramientas que pueden facilitar el desarrollo de alternativas sociales, culturales y económicas capaces de generar caminos hacia la emancipación social e individual. Por esto, no se trata de renunciar a todas las opciones que nos ofrecen los nuevos medios sino de tener claras sus limitaciones e intentar rectificar el rumbo de sus contenidos y el uso limitado (y socio-políticamente riesgoso) que le están dando la enorme mayoría de los usuarios.

\section{5- Trascender los límites de la Pantalla: otro mundo es posible}

El uso de medios digitales puede contribuir a transformar la realidad social facilitando la creación de formas novedosas de integración ciudadana que establezcan lazos culturales y de solidaridad entre las personas y entre grupos de personas pertenecientes a comunidades nacionales, étnicas o religiosas diferentes - prácticas que alejen a unos y a otros del modelo endogámico e hiperconsumista que promueve el infocapitalismo contemporáneo.

Internet solo será un aliado de la democracia de la mano de actores sociales que porten nuevos valores democráticos. Solo la alianza cada vez más evidente entre movimientos emancipadores y las nuevas tecnologías hará de éstas un instrumento liberador. (Candón Mena y Benítez Eyzaguirre (Eds.), 2017, p. 10)

Los nuevos medios digitales, pensamos, pueden contribuir a detener los procesos de atomización individualista que perpetúan y acentúan la discriminación y la exclusión social, cultural y económica de cerca de la mitad de la población mundial. Miles de millones de mujeres y hombres de todas las edades, semejantes, recordemos, a cada uno de nosotros. 
Conmovernos ante la imagen de un niño muerto ahogado intentando llegar a las costas de Europa, tierra prometida de los desesperados de la Tierra o de indignarnos al enterarnos de las condiciones de vida de los recolectores de yerba mate, de algodón o de café de nuestra América Latina es insuficiente. Es necesario que nos decidamos, como especie, a facilitar la vida de todas las personas arrancando de raíz los motivos que generan el hambre, la miseria y las guerras. Debemos entender que todos los seres humanos tenemos derecho a vivir dignamente y hacer lo (im)posible para conseguirlo. No tenemos que resignarnos a vivir en permanente alerta temerosos ante la presencia de los otros, cerrando los ojos ante la ignominia del hambre, de la falta de agua corriente y de condiciones sanitarias mínimas de millones de personas, dándole la espalda a las víctimas de la guerra y sosteniendo con nuestro consumo la sobreexplotación laboral y el trabajo semiesclavo.

Todo sistema de control, por más perfeccionado que sea, ofrece resquicios de vulnerabilidad. La resignación que se observa en amplias capas de la sociedad que rechazan las consecuencias visibles del hiperconsumismo sobre el planeta, puede revertirse mediante el desarrollo formas colaborativas de acción comunitaria que permitan la superación del individualismo mercantilista y de toda modalidad de discriminación. Es imprescindible eliminar el malestar, el miedo y el desencanto que avanzan sobre gran parte de la humanidad, incluso de muchos de aquellos que tienen acceso al confort material que brinda el dinero.

El triste hecho de que la oposición al sistema sea incapaz de articularse en forma de una alternativa realista, o al menos de un proyecto utópico significativo, y sólo pueda tomar forma de un estallido absurdo, es una seria denuncia de la situación en que nos encontramos (Zizek, 2016, p.47).

Las redes telemáticas son, en su origen, la expresión de valores socioculturales que muestran distintas formas de colaboración. En tal sentido, el acceso masivo y la 
versatilidad de los nuevos medios permite imaginar el surgimiento de movimientos emancipadores, cuyas propuestas transformadoras trasciendan los límites de la Pantalla y la mera protesta testimonial - propuestas que contribuyan a construir los cimientos de un mundo en que la igualdad y la libertad sean más que meros enunciados, en donde la miseria, el hambre, la discriminación y la guerra sean un recuerdo del pasado. "La utopía no es una pura fantasía. Es un no-lugar que puede, potencialmente, convertirse en un lugar." (Groys, 2016, p. 91)

El primer paso para comenzar a darle forma concreta a este lugar, es relacionarnos con el mundo desde fuera de la Pantalla y volver a la Pantalla para unirnos con nuestros semejantes creando redes duraderas entre personas que discutan sobre problemas comunes, establezcan objetivos y desarrollen planes de acción que favorezcan el desarrollo de nuevas condiciones de producción simbólica y material que permitan construir un mundo mejor, en el que quepamos todos los seres humanos, sin ningún tipo de distinciones. Como nos recuerda el colectivo Ippolita (2012), utilizar juntos una tecnología convivencial significa transformarse y transformar la realidad que nos rodea. Tengamos presente que la tecnología sólo puede servir para facilitar o acelerar algunos procesos. Es este el papel reservado a los nuevos medios: devenir una herramienta social valiosa para mejorar la vida de las personas, no un demiurgo. Confiemos en que así será.

\section{Referencias}

Barlow, J. P. (1996). Declaración de Independencia del Ciberespacio, Electronic Frontier Foundation. Wikisource. Recuperado de https://es.wikisource.org/wiki/Declaración_de_independencia_del_ciberespacio

Berardi, F. (2003). La fábrica de la infelicidad. Nuevas formas de trabajo y movimiento global. Madrid: Traficante de sueños. 
Candón Mena, J. y Benítez Eyzaguirre, L. (Eds.) (2016). Activismo digital y nuevos modos de ciudadanía: Una mirada global. Bellaterra: Institut de la Comunicació. Recuperado de http://incom.uab.cat/download/ebook_lucila_v4.pdf Comisión de las Comunidades Europeas (1993). Crecimiento, competitividad, empleo. Retos y pistas para entrar en el siglo XXI. Libro blanco. Boletín de las CE, Suplemento 6(93). Luxemburgo: Oficina de Publicaciones Oficiales de las Comunidades Europeas.

Fernández-Savater, A. (24 de julio de 2015). La pesadilla de un mundo en red [Mensaje en un blog]. Recuperado de http://www.eldiario.es/interferencias/pesadillamundo-red_6_412668752.html

Flichy, P. (2006). El individualismo conectado. Entre la técnica digital y la sociedad. Telos, (68), 13-25.

Fisher, M. (2016). Realismo capitalista ¿No hay alternativa?. Buenos Aires: La Caja Negra.

Forget, P. y Polycarpe, G (1990). L'homme machinal : technique et progrès. Paris : Syros-Alternative.

Groys, B. (2016). Arte en flujo. Ensayos sobre la evanescencia del presente. Buenos Aires: La Caja Negra.

Han, B-C (2015). La sociedad de la transparencia (1a ed.). Buenos Aires: Herder. Han, B-C (2015b). Psicopolítica. Buenos Aires: Herder.

Oxfam. (2016). Informe OXFAM. Recuperado de https://www.oxfam.org/es Ippolita (2012). En el acuario de Facebook. Madrid: Enclave de Libros. Lanier, J. (2015). ¿Quién Controla el Futuro? (1a de.). Buenos Aires: Debate. Levis, D. (1999). La Pantalla Ubicua (1a ed.). Buenos Aires: Ciccus/La Crujía. 
Magnani, E. (2017). Hacete amigo del Big Data. Revista Anfibia. Buenos Aires:

Universidad Nacional de San Martín. Recuperado de http://www.revistaanfibia.com/ensayo/hacete-amigo-del-big-data/

Masuda, Y. (1988). Computopía versos estado automatizado. En AAVV. Problemas en torno a un cambio de civilización (pp.111-127). Barcelona: El Laberinto.

PNUD / Programa de Naciones Unidas para el Desarrollo (2014). Informe sobre el Desarrollo Humano 2014. Sostener el Progreso Humano: reducir vulnerabilidades y construir resiliencia. Nueva York: PNUD.

Ramonet, I. (25 de julio de 1996). Nos han robado la esperanza. El País (p.13). Madrid: El País.

Sagastegui, D. (2005). La apropiación social de la tecnología. Un enfoque sociocultural del conocimiento. Razón y Palabra, (49).

Serrano, P. (2015). La comunicación jibarizada. Como la tecnología ha cambiado nuestras mentes. Madrid: Península.

Unión Internacional de Telecomunicaciones [ITU]. (2005). Cumbre Mundial Sociedad de la Información. Documentos Finales. Ginebra 2003 - Túnez 2005. Ginebra: ITU

Wiener, N, (1969). Cibernética y Sociedad. Buenos Aires: Sudamericana.

Wolton, D. (1992). Medias, novelles techniques de communication et l'eternelle idéologie techniciste. En Chambat, P. Communication et lien social. París: Descartes.

World Media Network (9 de marzo de 1995). World Media Network: habla el futuro El País, Suplemento.

Zizek, S. (2016). La nueva lucha de clases. Los refugiados y el terror. Barcelona: Anagrama. 
Formato de citación

Levis D. (2017). Inclusión digital no es inclusión social: De la ilusión de libertad al hiperconsumismo tecnototalitario. Psicología, Conocimiento y Sociedad, 7(2), 279-308. Disponible en: $\underline{\text { http://revista.psico.edu.uy/ }}$ 